\title{
$65 \mathrm{~nm}$ CMOS 기술에서 소자 종류에 따른 신뢰성 특성 분석
}

\author{
김창수 ${ }^{1}$, 권성규 ${ }^{1}$, 유재남 ${ }^{1}$, 오선호 $^{1}$, 장성용 $^{1}$, 이희덕 ${ }^{1, a}$ \\ 1 충남대학교 전자전파정보통신공학과
}

\section{Analysis of Reliability for Different Device Type in $65 \mathrm{~nm}$ CMOS Technology}

\author{
Chang Su Kim ${ }^{1}$, Sung-Kyu Kwon ${ }^{1}$ Jae-Nam Yu ${ }^{1}$, Sun-Ho Oh${ }^{1}$, Seong-Yong Jang ${ }^{1}$, \\ and Hi-Deok Lee ${ }^{1, a}$ \\ ${ }^{1}$ Department of Electronic Engineering, Chungnam University, Daejeon 305-764, Korea
}

(Received November 6, 2014; Revised November 19, 2014; Accepted November 21, 2014)

\begin{abstract}
In this paper, we investigated the hot carrier reliability of two kinds of device with low threshold voltage (LVT) and regular threshold voltage (RVT) in $65 \mathrm{~nm} \mathrm{CMOS} \mathrm{technology.} \mathrm{Contrary} \mathrm{to}$ the previous report that devices beyond $0.18 \mu \mathrm{m}$ CMOS technology is dominated by channel hot carrier(CHC) stress rather than drain avalanche hot carrier(DAHC) stress, both of LVT and RVT devices showed that their degradation is dominated by DAHC stress. It is also shown that in case of LVT devices, contribution of interface trap generation to the device degradation is greater under DAHC stress than $\mathrm{CHC}$ stress, while there is little difference for RVT devices.
\end{abstract}

Keywords: CHC, DAHC, SCE, Interface trap generation, Charge pumping

\section{1. 서 론}

$\mathrm{VLSI}$ 시스템이 점차 소형화, 휴대화 되어감에 따 라 다양한 응용분야에서 저 전력 (low power)이 중 요해지고 있다. 회로의 성능을 개선하고 한 칩에 더 많은 기능들을 집적하기 위해 소자의 크기는 계속해 서 축소되어왔다. 그러나 전력 소모 (power consumption) 증가와 칩의 온도 증가와 그리고 공정 기술이 축소됨에 따라, 전력 밀도 (power density)와

a. Corresponding author; hdlee@cnu.ac.kr

Copyright (C2014 KIEEME. All rights reserved.

This is an Open-Access article distributed under the terms of the Creative Common Attribution Non-Commercial License (http://creativecommons.org/licenses/by-nc/3.0) which permits unrestricted non-commercial use, distribution, and reproduction in any medium, provided the original work is properly cited.
전류 밀도 (current density) 증가하여 전기적 영향에 의한 결함 (electro-migration)과 신뢰성 문제가 대두 되고 있다 [1].

신뢰성 문제 중 하나인 핫 캐리어 (hot carrier) 열 화 현상은 $\mathrm{CHC}$ (channel hot carrier)와 DAHC (drain avalanche hot carrier) 두 가지로 분류된다 [2,3]. $\mathrm{CHC}$ 는 채널 양단에 걸리는 전계에 의해 채널 을 통과하는 전자 중 일부가 확률적으로 격자와의 충 돌을 하지 않고 가속되어 큰 에너지를 갖게 된 lucky electron이 oxide barrier을 넘어 산화막 내 trap으로 전자가 포획되는 것에 의한 열화로 설명되며, $\mathrm{V}_{\mathrm{G}}=\mathrm{V}_{\mathrm{D}}$ 조건에서 가장 많이 발생된다고 알려져 있다. DAHC 는 드레인 끝단에서 드레인과 기판 간에 인가된 전계 에 의해 가속되어 에너지를 얻은 전자가 격자와 충돌 
하여 전자-정공 쌍이 생성되고, 이러한 충돌 이온화 (Impact ionization)가 최대 $\left(\mathrm{V}_{\mathrm{G}} \sim \mathrm{V}_{\mathrm{D}} / 2\right)$ 가 될 때 가장 큰 열화 특성을 나타낸다. 일반적으로 $0.18 \mu \mathrm{m}$ 기술 이전의 소자에서는 $\mathrm{CHC}$ 보다 $\mathrm{DAHC}$ 에 의한 열화가 더 심하고 이를 기울기 (power law exponent)의 크 기 차이로 확인할 수 있었다 [3,4]. 그러나 소자가 더 scale-down되어 $0.18 \mu \mathrm{m}$ 기술 이후의 소자에서는 소 자의 열화가 심해지는 전압 조건이 $\mathrm{V}_{\mathrm{G}} \sim \mathrm{V}_{\mathrm{D}} / 2$ 에서 $\mathrm{V}_{\mathrm{G}}=\mathrm{V}_{\mathrm{D}}$ 으로 변화하고 있고, $\mathrm{DAHC}$ 보다 $\mathrm{CHC}$ 스트레 스에서 더 열화가 심한 것으로 보고되었다 [5-7].

최근에는 고성능의 소자 특성이 요구될 뿐 아니라, off 상태에서의 낮은 전력 소모까지 요구되고 있다. 이는 다중 임계전압 CMOS (multi-threshold voltage CMOS)기술을 통해 높은 (high threshold voltage, HVT), 기준 (regular threshold voltage, RVT), 낮은 (low threshold voltage, LVT) 임계 전압을 갖는 소 자를 선택적으로 사용함으로써 저 전력 및 고성능 사 양을 얻는데 주요 핵심 기술이 되고 있으며, 따라서 한 웨이퍼에 이러한 다양한 임계 전압을 갖는 소자들 을 구성하는 것이 필수화 되고 있어서, 같은 technology에서 다른 임계 전압을 갖는 소자들의 핫 캐리어 특성 변화 분석이 중요시 되고 있다.

본 논문에서는 $65 \mathrm{~nm} \mathrm{CMOS}$ 기술에서 다른 임계 전압을 갖는 소자들, 즉 임계전압이 낮은 소자 (LVT)와 기준 임계 전압을 갖는 소자 (RVT)에 대해 핫 캐리어 신뢰성 특성을 비교하였다. 특히 철저한 분석을 위해 $\mathrm{CHC}$ 와 $\mathrm{DAHC}$ 두 가지 스트레스 조건 에서 모두 소자의 수명 (lifetime)을 비교하고 소자에 따른 열화 특성과 그에 따른 메커니즘을 분석하였다.

\section{2. 실험 방법}

\section{1 소자 제작 및 측정}

본 논문에 사용된 소자는 $65 \mathrm{~nm}$ standard logic $\mathrm{CMOS}$ 기술을 이용하여 제작되었다. 유효 산화막 두 께 (equivalent oxide thickness)는 약 $1.25 \mathrm{~nm}$, 게이 트 넓이 (gate width)는 $20 \mathrm{um}$, 유효 채널 길이 (effective channel length)는 $60 \mathrm{~nm}$ 이며 채널 도핑 (channel doping)에 따른 $330 \mathrm{mV}$ (LVT), $430 \mathrm{mV}$ (RVT) 임계전압을 갖는 소자들이 제작되었다.

특정 드레인-소스 전압에서 드레인 영역에 수평 전 계가 최대가 되는 $\left(\mathrm{I}_{\mathrm{Sub} . \max }\right)$ 지점에서의 게이트 전압을
게이트-소스 스트레스 전압으로 $\mathrm{DAHC}$ 스트레스를 인가하였다. $\mathrm{CHC}$ 스트레스 조건은 드레인-소스 전압 과 게이트-소스 전압을 동일한 조건으로 설정하였다. 각 스트레스 조건에서 각 소자의 스트레스로 인해 포 화 드레인 전류 $\left(\mathrm{I}_{\mathrm{dsat}}\right)$ 가 $10 \%$ 변화하는 시간까지를 소 자의 수명으로 정의한 후, 동작전압 (operation voltage)의 1.1 배인 $1.1 \quad \mathrm{~V}_{\mathrm{DD}}$ 에서의 소자의 수명 (device lifetime)을 역 드레인 전압의 곡선 (lifetime versus $1 / \mathrm{V}_{\mathrm{D}}$ curve)으로부터 추출하였다. 또한 DAHC 와 $\mathrm{CHC}$ 스트레스에 따른 소자 특성의 변화 원인을 자세하게 파악하기 위해 핫 캐리어 전후에 전하 펌프 측정을 이용하여 계면 농도의 변화를 추출하였다.

\section{3. 결과 및 고찰}

그림 1 은 임계전압이 다른 소자들의 드레인 전류게이트 전압 $\left(\mathrm{I}_{\mathrm{D}}-\mathrm{V}_{\mathrm{G}}\right)$ 특성을 도시한 그래프이며, 그림 1 을 통해 추출한 파라미터를 표 1 에 정리하였다. 그 래프와 표에서 볼 수 있듯이, 채널 도핑 농도에 따라 LVT와 RVT 소자의 임계전압 $0.1 \mathrm{~V}$ 정도 차이를 보 였으며, 드레인 전류는 약 $82 \mu \mathrm{A}$ 차이를 보였으며, 두 소자 모두 매우 안정된 소자 특성을 나타냄을 알 수 있다.

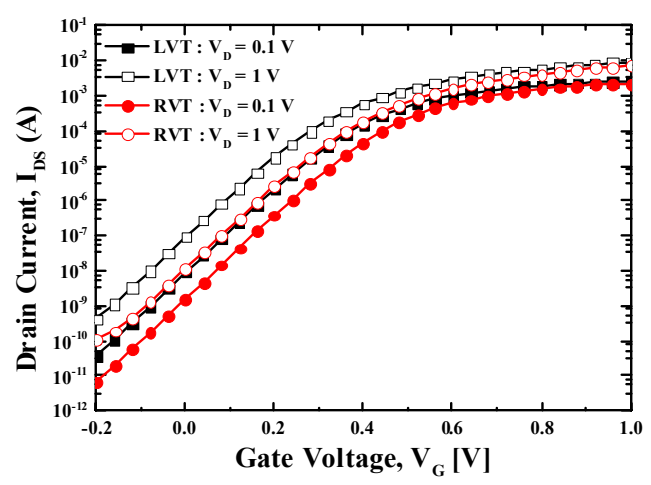

Fig. 1. Drain current vs. gate voltage $\left(\mathrm{I}_{\mathrm{D}}-\mathrm{V}_{\mathrm{G}}\right)$ characteristics of LVT and RVT devices.

Table 1. Extracted DC parameters of all devices.

\begin{tabular}{cccc}
\hline Device & $\mathrm{V}_{\text {T.ext }}(m V)$ & $\mathrm{I}_{\text {D.Sat }}(\mu A / \mu m)$ & $\operatorname{DIBL}(m V / V)$ \\
\hline \hline LVT & 330 & 459 & 96.3 \\
\hline RVT & 430 & 377 & 94.18 \\
\hline
\end{tabular}



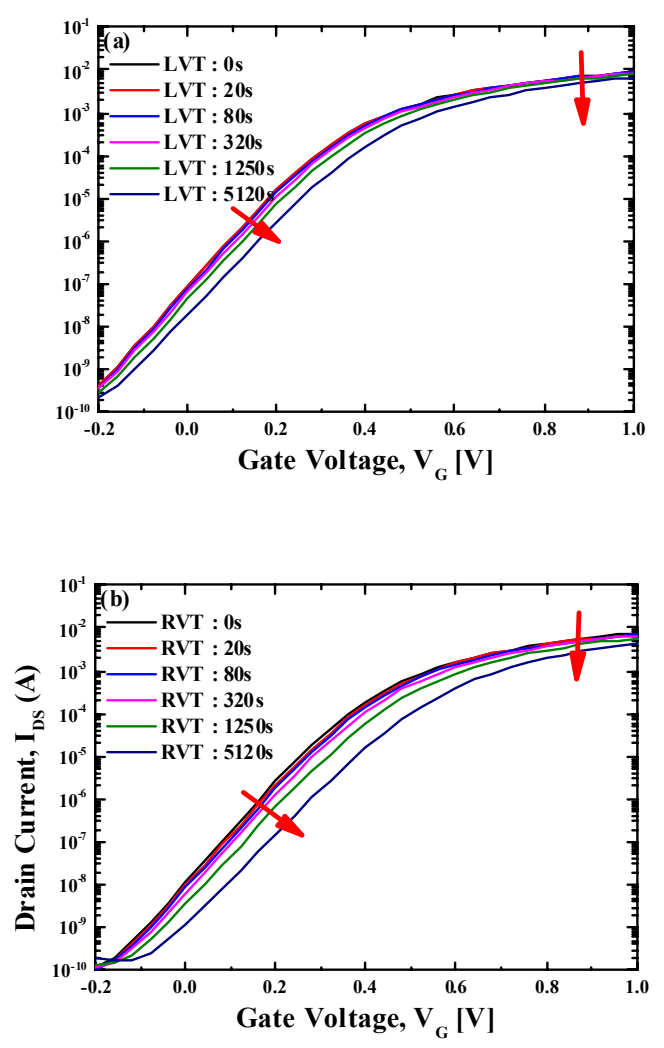

Fig. 2. Decrease of drain current by channel hot carrier stress for (a) low threshold voltage (LVT) and (b) regular threshold voltage (RVT) devices with stress voltage of $2.2 \mathrm{~V}$.

그림 2 는 동일한 산화막 두께와 서로 다른 임계전 압을 갖는 두 소자에 대해 hot carrier 스트레스 시간 에 따른 $\mathrm{I}_{\mathrm{D}}-\mathrm{V}_{\mathrm{G}}$ 특성의 변화를 보여주고 있다. LVT 소자와 RVT 소자 모두 스트레스 시간에 따라 임계 전압이 증가하고 드레인 전류가 감소하는 열화 (degradation) 특성이 나타나는 것을 알 수 있다. 이 러한 데이터를 이용하여 스트레스 시간에 따라 $\mathrm{I}_{\mathrm{Dsat}}$ $\mathrm{V}_{\mathrm{T} \text {.ext }}$ 파라미터들의 변화를 추출하였다.

그림 3은 시간에 따른 드레인 전류 변화율을 보여 주고 있다. 그래프에서 볼 수 있듯이 기울기 (power law exponent)는 열화 메커니즘을 나타내는 간접적인 지표라고 할 수 있다 [5]. LVT 소자에서는 $\mathrm{CHC}$ 에서 보다 $\mathrm{DAHC}$ 에서 기울기가 크고 계면 트랩 준위 생성 이 우세하였다. RVT 소자에서는 $\mathrm{CHC}$ 와 $\mathrm{DAHC}$ 에서 비슷한 기울기를 나타내고 있다. 일반적으로 $\mathrm{CHC}$ 스 트레스가 인가된 경우에는 산화막 내의 전하 포획이

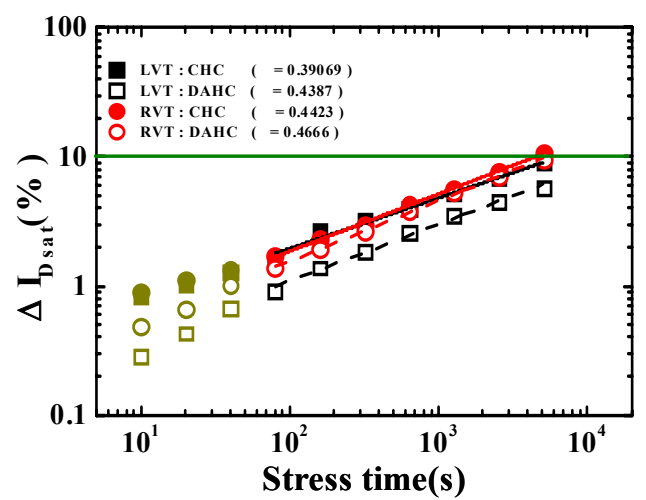

Fig. 3. Variation of drain current, $\Delta \mathrm{I}_{\mathrm{D} \text {.Sat }}(\%)$ of $65 \mathrm{~nm}$ devices by DAHC and CHC stress.

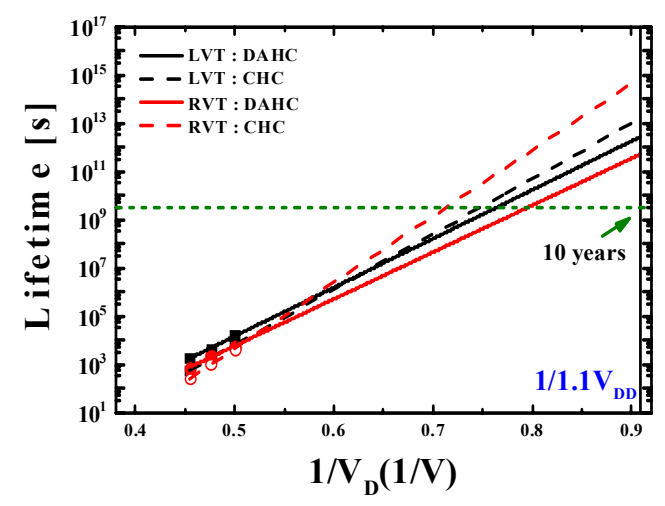

Fig. 4. Extraction of hot carrier lifetime.

우세하여 기울기가 약 0.3 의 값을 가지며, $\mathrm{DAHC}$ 스 트레스에서는 전하 포획 보다는 계면 준위 생성이 우 세하여 기울기가 약 0.5 내외를 갖는다는 기존 보고 와 달리 [4], $\mathrm{CHC}$ 에서도 약 $0.4 \sim 0.5$ 의 기울기를 나타 내고 있다. 이는 본 실험에서 사용된 $65 \mathrm{~nm}$ 소자인 경우 게이트 산화막 특성, 소스/드레인의 도핑 구조, 채널의 구조 등이 복합적으로 작용하여 $\mathrm{CHC}$ 스트레 스 조건에서도 계면 트랩 준위 생성이 우세하게 발생 한다는 것을 나타낸다고 할 수 있다. 즉, 채널 길이 축소, 산화막 두께 축소에 따라 채널 내에 존재하는 수평 및 수직 전계, 충돌 전이계수 (impact ionization factor)의 증가와 발생 위치에 따라 $\mathrm{CHC}$ 역시 $\mathrm{DAHC}$ 스트레스와 유사하게 계면 트랩 준위 생성 메커니즘 으로 변경된 것이라 판단된다.

그림 4 는 임계 전압이 다른 두 소자들의 수명을 역 드레인 전압의 곡선 (lifetime versus $1 / \mathrm{V}_{\mathrm{D}}$ curve)으 

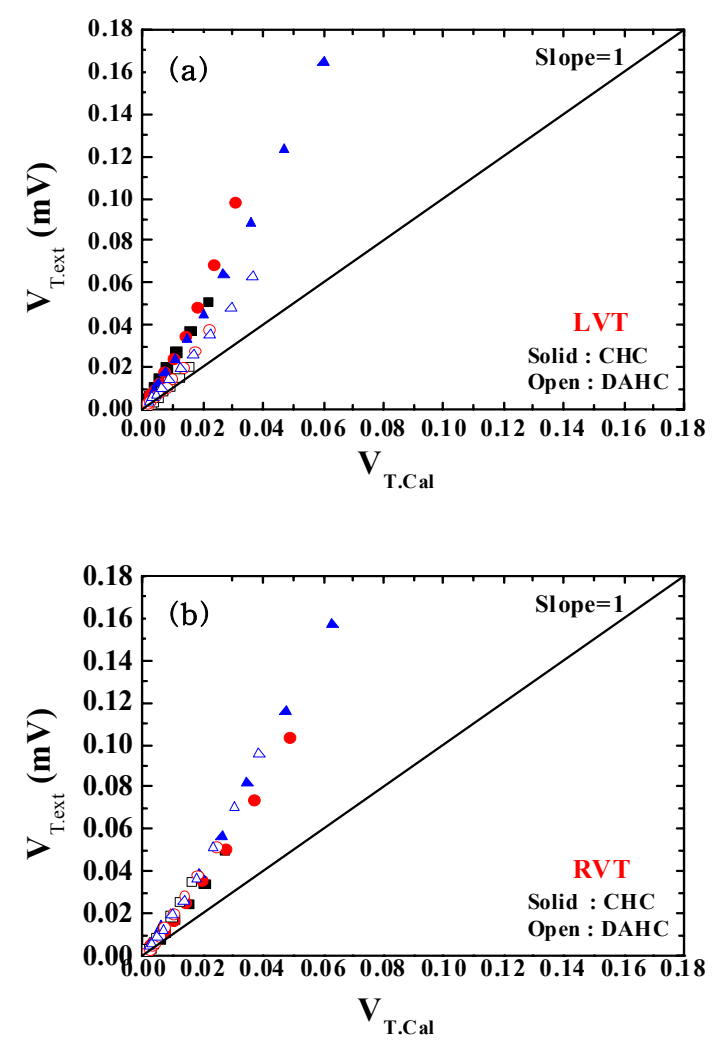

Fig. 5. Correlation the $\mathrm{V}_{\text {T.ext }}$ in DC degradation and the $\mathrm{V}_{\text {T.Cal }}$ calculated from $\mathrm{N}_{\mathrm{it} .}$ (a) LVT and (b) RVT.

로 추출한 것을 나타내고 있다. $0.18 \mu \mathrm{m}$ 기술 이하의 소자에서는 $\mathrm{CHC}$ 에 의한 열화가 $\mathrm{DAHC}$ 에 의한 열화 보다 크다는 기존 보고와 달리 [7], 그림 4에서 볼 수 있듯이 LVT와 RVT 소자 모두 DAHC 스트레스에서 열화가 더 심한 것을 볼 수 있었다. 이는 $\mathrm{CHC}$ 보다 $\mathrm{DAHC}$ 스트레스 시에 계면 트랩 준위 생성 비율이 크기 때문에 DAHC 스트레스에 의한 열화가 심한 것 이라고 추측이 가능하다.

그림 5 는 그림 4 의 열화 특성에 대해 좀 더 구체적 인 메커니즘을 파악하기 위해서 핫 캐리어 스트레스 에 의한 임계전압 변화와 $\left(\Delta \mathrm{V}_{\text {T.ext }}\right)$ 과 전하 펌핑 기술 을 통해 얻어진 interface trap 농도를 이용하여 계산 된 임계 전압 변화 $\left(\Delta \mathrm{V}_{\text {T.Cal }}\right)$ 간의 연관성 (correlation) 을 보여 주고 있다.

식 (1)은 핫 캐리어 스트레스에 따른 임계전압의 변화를 나타내는 식으로 $\Delta \mathrm{Q}_{\mathrm{it}}$ 는 계면 트랩에 의한 전 하의 변화량, $\Delta \mathrm{Q}_{\mathrm{ot}}$ 는 산화막 내의 포획에 의한 전하
의 변화량을 나타내고 $\mathrm{C}_{\mathrm{ox}}$ 는 산화막의 캐패시턴스를 나타낸다 [5].

$$
\Delta V_{T}=\frac{\Delta Q_{i t}+\Delta Q_{o t}}{C_{o x}}
$$

즉, 핫 캐리어에 의해 열화된 임계전압 $\left(\Delta \mathrm{V}_{\mathrm{T} \text {.ext }}\right)$ 은 계면 트랩생성에 의한 것과 산화막 내에 전하 포획에 의한 것이 모두 영향을 미칠 수 있음을 알 수 있다. 그리고 전하 펌핑 기술을 통해 추출된 임계전압의 변 화량 $\left(\Delta \mathrm{V}_{\mathrm{T} . \mathrm{Cal}}\right)$ 은 순수하게 계면 트랩 생성에 의한 것 으로, 이 두 임계전압을 연관 했을 때, 기울기가 1 에 가까우면 핫 캐리어 스트레스에 소자 열화가 계면 트 랩 생성에 의한 것이 우세하다는 것을 알 수 있다.

결과적으로 그림 5(a)에서 볼 수 있듯이 LVT 소자 는 $\mathrm{DAHC}$ 스트레스인 경우가 $\mathrm{CHC}$ 스트레스인 경우 에 비해 기울기가 1 에 더 가까운 것을 통해 계면 트 랩 준위 생성에 우세한 것을 알 수 있다. 또한, 그림 5(b)의 RVT 소자는 DAHC와 $\mathrm{CHC}$ 스트레스 모두 계면 트랩 준위 생성 보다는 산화막 내의 전하 트래 핑이 더 우세한 것을 알 수 있다.

\section{4. 결 론}

본 논문에서는 $65 \mathrm{~nm} \mathrm{CMOS}$ 기술에서 일반 임계 전압을 갖는 소자와 낮은 임계 전압을 갖는 소자들의 신뢰성을 비교 분석하였다. 소자가 Scale-down 됨에 따라 핫 캐리어에 의한 열화가 주로 $\mathrm{DAHC}$ 에서 $\mathrm{CHC}$ 로 변화된다는 일반적인 보고 내용과 달리, 본 논문에서 측정된 $\mathrm{LVT}, \mathrm{RVT}$ 소자 모두 $\mathrm{DAHC}$ 스트 레스에서 열화가 심하고 짧은 수명을 나타내었다. $\mathrm{RVT}$ 소자인 경우에는 $\mathrm{CHC}$ 와 $\mathrm{DAHC}$ 스트레스에서 모두 동일한 소자 열화 메카니즘을 나타내는 것에 비 하여, $\mathrm{LVT}$ 소자에서는 $\mathrm{CHC}$ 보다 $\mathrm{DAHC}$ 인 경우에 interface trap의 발생에 의한 소자 열화가 더 크게 나타남을 알 수 있었다.

\section{감사의 글}

이 연구는 삼성전자(주)와 충남대학교 학술연구비 에 의해 지원되었음. 소자 제작은 IDEC (IC Design Education Center)의 지원으로 이루어 졌음. 


\section{REFERENCES}

[1] H. Jiao and V. Kursun, IEEE J. of Solid-State Circuits, 644 (2012)

[2] M. J. Cho and P. Roussel, IEEE Trans. Electr. Dev., 60, 4002 (2013).

[3] B. Doyle, K. R. Mistry, and J. Faricelli IEEE Trans. Electr. Dev., 18, 51 (1997).

[4] C. Hu and S. C. Tam, IEEE Trans. Electr. Dev.,
ED-32, 375 (1985).

[5] B. Doyle, M. Bourcerie, and J. C. Marchetaux, IEEE Trans. Electr. Dev., 37, 744 (1990).

[6] K.R.B. Doyle, IEEE Trans. Electr. Dev., 40, 96 (1985).

[7] S. G. Lee, J. M. Hwang, and H. D. Lee, IEEE Trans. Electr. Dev., 49, 1876 (2002).

[8] E. Amat, T. Kauerauf, and R. Degraeve, IEEE Trans. Electr. Dev., 9, 425 (2009). 